\title{
Corpos fraturados nas colagens de Max Martins
}

\author{
Fractured bodies in Max Martins collages \\ Márcia de Souza PINHEIRO* \\ Universidade Federal do Pará (UFPA) \\ Tânia Maria Pereira SARMENTO-PANTOJA** \\ Universidade Federal do Pará (UFPA)
}

RESUMO: O corpo (objeto de arte) é um personagem histórico que marcou seu território nos movimentos artísticos. Por esse motivo, tornou-se objeto de pintura, escultura, colagens, com isso, obteve versões plurais de visibilidade e concepções, marcando não apenas os trabalhos de Giotto de Bondone, Leonardo da Vinci, Man Ray, assim como muitos outros artistas tiveram destaque no decorrer do tempo. Na contemporaneidade, destacamos a colagem de Max Martins, que também confere sua abordagem à temática. Assim, este artigo pretende analisar os corpos fraturados: fragmentados, desfigurados, quebrados e deformados na colagem de Max Martins, considerando os aspectos estéticos, simbólicos e intertextuais.

PALAVRAS-CHAVE: Max Martins. Colagem. Corpo. Fratura.

ABSTRACT: The body (object of art) is a historical personage that marked its territory in the artistic movements. For this reason, he became an object of painting, sculpture, collages, with which he obtained plural versions of visibility and conceptions, marking not only the works of Giotto de Bondone, Leonardo da Vinci, Man Ray, as well as many other artists In the course of time. In contemporaneity, we highlight the collage of Max Martins, who also confers his approach to the theme. Thus, this article intends to analyze the fractured bodies: fragmented, disfigured, broken and deformed in Max Martins' collage, considering the aesthetic, symbolic and intertextual aspects.

KEYWORDS: Max Martins. Collage. Body. Fracture.

Recebido em 13 de dezembro de 2016. Aprovado em 15 de dezembro de 2016.

\footnotetext{
*Graduada em Letras - Habilitação em Língua Portuguesa - UFPA (2013). Mestre em Letras, Área de Concentração: Estudos Literários - UFPA (2016). Professora de Literatura na Instituição de Ensino fundamental e médio "Dom Ângelo Frozi”" (Barcarena-Pará). E-mail: marciasouzaletras03@ gmail.com

${ }^{* *}$ Docente da Graduação em Letras Língua Portuguesa (FALE/ILC) e do Programa de Pós-Graduação em Letras (UFPA). Coordenadora do Programa de Pós-Graduação em Letras /UFPA (2015-2017). Líder do Grupo de Pesquisa Estudos sobre Narrativa de Resistência (NARRARES). Bolsista Produtividade em Pesquisa - CNPQ (CALL 2). Membro da Diretoria da Associação Brasileira de Literatura Comparada ABRALIC (2014-2015). E-mail: nicama @ufpa.br.
} 


\section{Introdução}

Este artigo objetiva analisar o corpo fraturado na colagem de Max Martins, destacando seus aspectos simbólicos, estéticos e intertextuais. Assim, investigamos o imaginário do corpo na história da arte a partir da Modernidade, ressaltando as influências cubistas, surrealistas e a proeminente desumanização da obra de arte moderna, que cultiva o homem como experiência artística, promovendo sua estilização.

As colagens de Martins revelam um jogo fascinante de criação artística e um mundo habitado por associações previstas e imprevistas, de ganhos e perdas. Da disposição do espaço da página, a ordem aleatória dos elementos, dos desmontes a reelaborações de objetos, de contextos, o poeta obtém um processo inquietante com as palavras/imagens, transformando-as em linguagens dispersas, desgastadas, aglomeradas, engendradas a recursos imagéticos que "falam" e "pedem" para serem interpretados. Não é à toa que o poeta se apropria de poesias, recortes e os resgata para um novo contexto. Nesse enfoque, suas colagens vão acoplando signos e linguagens, ampliando o repertório da significação, contextualizando os processos históricos e deixando inúmeros rastros dessa produção em sua poética.

Na história da arte, o corpo (objeto de arte) se transformou em alvo de pintura, escultura, colagens e um espaço de discussão e quebra de tabus. Em diferentes fases históricas se notabilizou, adquirindo concepções artísticas, filosóficas. Martins é um dos artistas contemporâneos que também fez do corpo um interessante espaço de produção de poesias e colagens. Técnica que obteve notoriedade nos movimentos de vanguarda europeia como, por exemplo, Cubismo e Surrealismo.

Cubismo e surrealismo fizeram diferentes usos da colagem, possibilitando a construção de um universo rico, híbrido para a composição dessa técnica ampliando suas formas de reprodução.

\section{Cubismo e surrealismo}

As vanguardas europeias do início do século XX são manifestações artísticas que propiciaram a disseminação de uma nova arte no ocidente ao se oporem às tendências vigentes e consentiram inúmeras contribuições para o campo artístico,

mais do que uma simples tendência, a vanguarda representa a mudança de crenças experimentadas no pensamento e na arte no 
mundo ocidental, desde o início deste século. Toda vanguarda sempre se caracteriza pela sua agressividade, manifestada no antilogismo, no culto a valores estranhos (o negrismo dos cubistas, os poderes mágicos, a beleza da anarquia, o instantaneísmo, o dinamismo, a imaginação sem fio, enfim (TELES, 1983, p. 82).

O cubismo via no processo de destruição de uma ordem a oportunidade de criar novos aspectos, gerar outros formatos artísticos. É uma tendência que privilegiava uma nova arquitetura estética e social. É sob esse olhar que o Cubismo e seus ideais relacionados ao "espírito nove" pregavam o discurso da construção da magia, da beleza interna (concentrada na composição de símbolos) que figuravam com aspectos tipicamente ligados aos elementos culturais inerentes à humanidade. É nessa recomposição artística que temos a grande contribuição cubista, enquanto vanguarda. Nessa perspectiva, as palavras de ordem consistiam em disseminar ideias de “destruição" e "construção", tornando-se, portanto, composições ou faces de uma mesma natureza. Desse modo, os aspectos cubistas "ordenados" e "caóticos"de uma representação figuravam juntos (idem, p. 84).

Assim, "poetas e pintores partilhavam um ideal comum de renovação artística: os poetas assimilando as técnicas pictóricas, os pintores se apoiando nas ideias filosóficas e políticas. [...] o termo cubista, aplicado à pintura, passou a [...] designar [...] poesia [...]". (idem, p. 114). Surgia, assim, um tipo de poética que se baseava em mostrar uma realidade decomposta, fracionada, em que aspectos como os planos superpostos eram constantes. Aliás, não podemos deixar de enfatizar que essa aplicabilidade ou tendência descrita no plano artístico tem origens históricas, pois foi fortemente influenciada pela junção de pintura à poesia praticada por Apollinaire. De modo que vários foram os artistas que se baseavam nas obras dele, o viam como fonte de inspiração para compor as suas obras, principalmente, no aspecto que primava pela alteração do real em formas geometrizadas.

A pintura cubista se desenvolveu e utilizou a técnica da decomposição da realidade, diversas estruturas a restituíam em formas geométricas. Era um processo intenso e criativo feito de desmontes de objetos. Assim:

no desejo de transmitir a estrutura total do objeto, os cubistas começaram a decompor as formas em diferentes planos geométricos e ângulos retos, que se interceptam e sucedem. Tentavam sugerir a representação do objeto sob todos os seus aspectos, de face e perfil, em suma, na sua totalidade (idem, 1983, p. 115). 
É justamente essa aparência, que sucede do objeto, a pretensão dos cubistas em expressar uma visão de todos os ângulos que o compõem, como se um observador contemplasse todas as suas faces montadas pela técnica da representação dessa realidade. Nesse enfoque, também é essencial destacar que a linguagem apresentou um papel primordial, pois foi sobre ela que recaíram algumas tarefas, a saber, o impulso das "forças destruidoras" as quais influenciaram a poesia brasileira.

Do surrealismo, convém salientar que se trata de um movimento motivado pelo "espírito novo", com um ideal de construção e reconstrução, oriundo dos destroços da grande guerra, que já profetizava sua presença em obras cubistas, a saber, as de Apollinaire.

É nessa perspectiva que a poesia passou a ser explorada em todos os sentidos e capacidades, rompendo os limites impostos pela razão, sendo explorada em habilidades poéticas, na pintura ou na existência cotidiana. $\mathrm{O}$ primordial na mentalidade mágica do projeto surrealista consistiu em reunificar e admitir um paralelo entre poesia, magia, loucura, etc, já que a arte primitiva no que tange às realizações plásticas e literárias assegurava que a magia promovia ao artista estar em contato direto e total com o universo.

No Manifesto Surrealista, Breton declarou a existência de uma história do Surrealismo, acrescentando existir uma "presença" e "consciência" essenciais, que o registravam como "prática de existência". O surrealismo também fez diferentes usos da colagem, colaborando com um universo de expectativas amplo para a composição dessa arte. Os surrealistas acreditavam que o uso da imagem supostamente real poderia adquirir outros aspectos, com itens plásticos, transformando-se em arte surrealista. Ernst, por exemplo, realizou suas primeiras experimentações e obteve seus resultados em seus quadros: O edipus Rex, (1921), A revolução à noite (1923), “Os homens não saberão de nada, (1923), as quais são realizações obtidas através das colagens e que foram reconhecidas no universo surrealista. O surrealismo também teve um importante papel ao explorar o corpo como objeto de arte, transformando-o em diversas composições, alterando seus formatos, operando corpos fraturados. 


\section{Corpos fraturados}

O corpo é uma compleição física, uma matriz ideológica, um território que fomenta identidades, concepções, teorias. Suas experiências expressam possibilidades de compreensão, inspirando-se em dessemelhantes abordagens e interações. Muitos são os agenciamentos que o empreendem até nos debruçarmos na histórica fragmentação.

É nesse sentido que o artista contemporâneo começou a se expressar por meio de formas humanas que registram a perda de partes de sua estrutura, sua inteireza si diluiu e originou lacunas e desintegrações - traços característicos da modernidade. O homem, sua essência, valores e leis gerais foram se dissolvendo no mundo moderno, distanciando-se de sua integridade original; o detalhe virou registro captado por artistas; a destruição da figura humana se originou sob a ótica das guerras mundiais. $\mathrm{O}$ olhar vanguardista esculpiu um retrato daquilo que significou a perpetuação e propagação do ser humano.

Neste viés, as representações do corpo fragmentado têm implicações voltadas à perda da inteireza e degradação estruturais que tornam o corpo um ponto central. Nele, temos conteúdo, realidade, ficção, montagens e desmontagens, tudo isso constitui os múltiplos saberes, conhecimentos e sua perpetuação histórica. Da biologia às artes, o corpo se estrutura, é um local de expressão artística, de vivências estéticas na modernidade, pois

a constante presença do corpo fragmentado é uma metáfora da perda da totalidade que concretiza a modernidade. O homem é apenas efêmero, um fragmento do mundo contingente e errante. A essência humana, desprovida de sua origem divina, apresenta-se como finitude e transitoriedade (idem, p. 36).

As colagens de Martins ilustram bem essa ideia de finitude, pois nessas ilustrações as fraturas são as marcas da desintegração sofrida pelo corpo que gerenciou desdobramentos, transformando-se em rostos, olhares, traços, pedaços, fisionomias, corpos fragmentados.

O corpo fraturado é uma estrutura que perdeu sua inteireza, sendo, portanto, recriada a partir de remontes de partes de outros $\operatorname{corpos}^{1}$, objetos, deslocados de diversas superfícies. É uma corpulência ressignificada que se relaciona em uma mesma

\footnotetext{
${ }^{1}$ Estamos tratando do corpo objeto de arte.
} 
colagem e de uma colagem para outra, enfatizando a decadência das formas desfeitas, suprimidas, fragmentadas.

Considerando algumas abordagens em torno do corpo objeto de arte, cabe acrescentar que os ideais que regiam as bases das "leis gerais" relacionadas à noção de integridade da vida, assim como aquilo que influenciava todo o comportamento humano dissolviam-se diante da dispersão que caracterizava o mundo com aspectos modernos.

Em relação à desumanização da obra de arte moderna, Ortega Y Gasset (1999) enfatiza que a nova época busca remover o homem do centro do mundo, afastando-o das concepções estéticas do realismo e do humanismo. Isso significa estilizar o aspecto humano, isto é, desumanizá-lo.

Neste sentido, a arte começa a ilustrar a figura humana cada vez mais rasurada, fraturada e dilacerada com fortes imagens de destruição, aniquilamento do aspecto humano, desumanizando-o. Constata-se, portanto, a perda de partes do corpo. Dessa maneira, o artista contemporâneo estiliza e deforma sua arte, inibindo a presença das formas humanas em suas representações, distanciando-as de sua origem, algo muito semelhante ao que acontece na colagem de Martins, posta a seguir. 


\section{As citações}

Figura 1: Colagem-corpo-01. Ano de produção: 1982 - 1998. Diários de Max Martins. A plástica entre parêntesis ${ }^{2}$

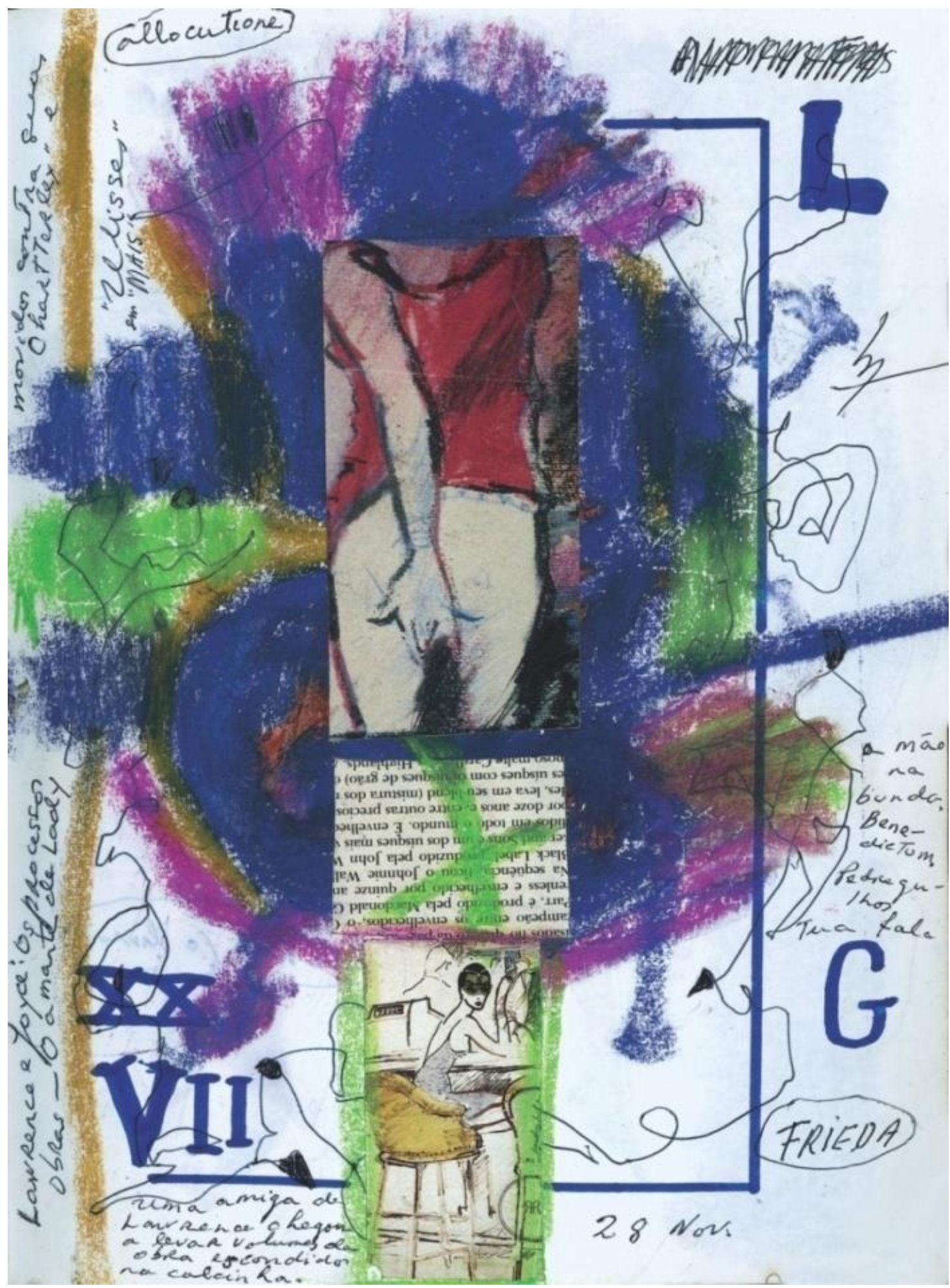

${ }^{2}$ Disponível em: http://www.culturapara.art.br/maxmartins/maxdiario.htm. Acesso em: 31 jan. 2017. 
A colagem-corpo-01 é composta por um tronco sem cabeça de costas (como lembra a pose de Kiki) e o fato de estar sem essa parte do corpo comprova sua fragmentação, mas este tronco possui um esboço de uma possível cabeça, diferente de sua integridade corporal. As partes superiores e inferiores do tronco aparecem revestidas por misturas de cores: azul, verde, lilás e outras tonalidades. Sua parte inferior está totalmente despida, enfatizando o tronco nu. Apenas uma mão é visível, a outra foi suprimida, mas essa mão está direcionada para a parte íntima do sujeito, que põe " $a$ mão na bunda” (algo que se confirma no conteúdo imagético e verbal).

Ao lado desse tronco e ainda na parte superior há a tímida presença de uma bota (em tons de azul). Abaixo do corpo-tronco aparece a imagem de uma jovem mulher sentada em uma cadeira próxima a um objeto, provavelmente uma mesa ou escrivaninha (como se estivesse escrevendo ou refletindo). Ao lado dessa mulher aparece um objeto não identificado com a seguinte inscrição: "7500". Ao lado desse objeto há traços mínimos de um corpo fragmentado masculino, pouco elucidativo. Um braço dessa jovem foi inibido e o seu olhar é de alguém que de repente se distraiu. Ela usa óculos estranhos e em tons de verde. Ao lado dela, os poucos vestígios refazem a imagem de um dos braços de outro sujeito, a proximidade entre ambos expressa o contato entre os corpos, apesar de a ilustração novamente camuflar partes corporais nessa representação. Além disso, a imagem é preenchida por outras rasuras, fragmento de jornal e setas que parecem indicar para aquilo que está posto na imagem.

A colagem é uma representação composta por rastros: cortes, traços, fraturas reinventadas em novas modalidades e misturas. A pintura é um elemento muito importante na composição dessa imagem, pois se torna o fundo colorido que rasura os sentidos, acolhe os corpos e os diversos discursos apontados pelo verbo, assim como o fragmento de jornal posto de cabeça para baixo. O corpo-tronco nu está próximo ao verbo, às falhas e traços rasurados.

A textura e a composição estampam a imagem de um corpo feminino recortado e em cores que mostra uma representação desfigurada: um tronco em meio às "desconstruções". Dessa maneira, a imagem dinamiza o corpo-textual que anuncia outros discursos:

"allocutione"/movidos contra Suas ChaRTTeRley'e "UliSSes" em Mais" LawRence e Joyce: Os processos Obras - O amante de Lady 
XX/VII Uma amiga de LawRence chegou a levar volumes da obra escondidos na calcinha/[...] Campeão entre os envelhecidos, o [...] Parr, é produzido pela Macdonald [...] enless e envelhecido por quinze anos [...]. Na sequência ficou o Johnnie Wal Black Label, produzido pela John [...] Sons e um dos uísques mais [...] vendidos em todo o mundo. E envelhecido por doze anos e, entre outras preciosidades, leva em seu blend (mistura dos [...] uíques com os uisques de grão [...]"'/A mão na bunda. Benedic-tum Pedregulhos Tua fala/G/FRIEDA /28 de Nov"/ "7500"(Colagem-Corpo 03).

Assim, o corpo-textual: "allocuttione" é um vocábulo de origem francesa, que traduzido para o português significa "alocução", verbo que cumpre sua "função" na disposição do corpo-tronco, pois anuncia um discurso curto e isolado posto na parte superior da colagem. O corpo verbal desta ilustração propõe diálogos inteiros e fragmentados e essa espacialização do verbo confirma a perda da integridade discursiva, mostrando como o corpo fraturado surge de supressões que comprometem o seu sentido original.

Nesse sentido, há um deslocamento do ato comunicativo, a escrita se fragmenta e se dilui inteiramente, mas o discurso prossegue: "movidos contra Suas ChaRTTeRley' e "UliSSes" em Mais" LawRence e Joyce: Os processos Obras - O amante de Lady XX/VII Uma amiga de LawRence chegou a levar volumes da obra escondidos na calcinha”. Martins cita rasuradamente: O Amante de Lady Chatterley (1928), de D.H. Lawrence e Ulisses (1922), de James Joyce - obras que viveram "processos". É a partir dessas pegadas verbais, deixadas pelo poeta, que interpretamos esses "processos".

$O$ Amante de Lady Chatterley narra à história de Constance Chatterley, uma jovem mulher recentemente casada, que enfrenta a realidade de uma inesperada separação de Clifford, seu marido, ao vê-lo partir para a guerra. No decorrer do tempo, ele retorna para seu lar, após ter sofrido um acidente que lesionou seus movimentos corporais, paralisando seus membros inferiores. Clifford - extremamente preocupado com seus negócios - se distanciava de sua esposa. Diante dessa situação: solitária e "distante" do marido, Constance desviou seus olhares para Oliver Mellors - um sujeito que também teve experiências amorosas frustradas, iniciando um relacionamento amoroso proibido.

Com base nisso, $O$ Amante de Lady Chatterley foi considerada uma obra proibida no início do século XX e abolida em seu lançamento, em 1928, sendo editada oficialmente em 1960 pela editora Penguin. Após essa edição, a editora foi penalizada 
com um processo jurídico por contribuir na divulgação de conteúdo inapropriado para o leitor.

Em virtude disso, por volta do mês de outubro de 1960, Griffith-Jones, em exercício como promotor público, resolveu trazer a júri uma inquietante discussão em relação à legalização dessa obra, justamente por conter em sua narrativa contextos que iam de encontro aos valores morais e éticos, pois segundo ele disseminava ideias capazes de perverter o leitor.

Diante disso, destacamos que, em Obras-primas no banco dos réus, Maria Pallares-Burke comenta que $O$ Amante de Lady Chatterley e Ulisses foram obras postas no cerne de uma discussão jurídica que consistia na proibição de suas respectivas publicações, considerando que cada uma delas foi editada em períodos distintos, apesar disso, ambas sofreram "processos", em virtude de seus conteúdos terem sido considerados obscenos, dificultando suas publicações.

Ressaltamos que a obra de Lawrence sofreu com o "processo" em questão. Processo que teve início quando a editora Penguin Books reproduziu milhares de cópias e vendeu por valores irrisórios a obra "proibida". Essa publicação não autorizada teve uma série de desdobramentos, principalmente por parte da mídia europeia, que difundiu significativamente essa questão, dando ênfase ao julgamento de $O$ Amante de Lady Chatterley, transformando-o em um verdadeiro "espetáculo". Esse procedimento teve uma duração de 32 anos, e, durante todo esse tempo, o livro esteve sob a ilegalidade, despertando inúmeras críticas, posicionamentos favoráveis e divergentes (PALLARESBURKE, 1997).

À medida que $O$ Amante de Lady Chatterley se consolidava como obra, a preocupação de Lawrence com os recursos financeiros para custeá-la cresciam, já que o livro continha uma linguagem "inadequada" para a sociedade. A solução para este empecilho foi Lawrence financiá-la. Isso garantiu a fidelidade do texto, e abolia o risco de censura. Com a obra publicada a censura britânica estava disposta a impedir isso. Essa tentativa ilegal de divulgação da obra ocasionou uma situação inusitada vinda de uma amiga de Lawrence, pois numa ocasião "sua amiga, por exemplo, chegara a carregar em sua calcinha alguns volumes da obra proibida" (idem). Um ato como esse revela a dificuldade de circulação dessa obra e a boa vontade dos amigos de Lawrence. 
Após uma série de questões que envolveram a obra de Lawrence, o autor faleceu. Somente décadas mais tarde, sua obra foi publicada oficialmente, sendo disponibilizada para o leitor no Reino Unido.

É interessante destacar que anos antes a célebre obra Ulisses também foi alvo de um "processo" - críticas e dificuldades - de aceitação por parte do público leitor, sendo considerada obscena e corrupta. Por causa disso, as autoridades norte-americanas realizaram um julgamento para decidir a respeito da legalidade dessa obra.

Diante disso, a revista “The Little Review" publicou entre 1918 e 1920 a obra Ulisses. Como já dissemos, a obra enfrentou duras críticas e resistência também em virtude de seu conteúdo. Esta revista foi acusada de contribuir com a difusão de conteúdos obscenos. Como consequência disso, a revista sofreu punições. Iniciou-se, então, uma luta jurídica em favor da publicação dessa obra. Naquele momento, a base jurídica em favor da livre circulação da obra não teve êxito, apesar de afirmar que o livro não sugeria a sexualidade apontada pelo júri (idem).

Nesse enfoque, a ordem dos advogados de Nova York foi o palco de um dos mais enfáticos julgamentos literários da história. A apreciação em torno das obras foi sendo conduzida pelo advogado de defesa e o promotor, a audiência foi "amistosa", e a decisão final conduziu todo o desenrolar desse "processo" (idem).

A sentença proferida por Woolsey foi contrária à censura de Ulisses, pois, "tão logo se suprime algo, o contrabandista entra em cena" (idem). Segundo Pallares-Burke, a visão dos observadores da audiência foi um dos grandes momentos desse processo, o discurso de defesa salientava que quanto mais a obra fosse proibida, mais sua curiosidade seria despertada.

Pallares-Burke entende que a sentença de Woolsey privilegiou questões relacionadas à mente, referenciando a intricada relação humana como norteadora das experiências cotidianas e seus efeitos na maneira de ser do sujeito. Sob essa perspectiva, conclui:

a obscuridade de muitas passagens, bem como o uso de palavras indecentes eram, segundo Woolsey, aspectos obrigatórios desse esforço hercúleo de reconstituir a vida interior dos indivíduos, onde o inteligível, o sublime, o ininteligível e o asqueroso muitas vezes se sucedem e se confundem. Lendo o livro na sua totalidade, e não em passagens isoladas, ficava evidente, argumentara Woolsey, que "Ulisses" fora escrito sem "intenção pornográfica" e que a excessiva 
preocupação dos personagens com temas sexuais fazia parte do realismo do autor [...] (idem).

Diante desta discussão, outros desdobramentos estiveram presentes no discurso de Woolsey, favoráveis à legalização de Ulisses, sendo o livro admitido nos Estados Unidos. Encerrado este difícil julgamento, nenhum discurso contrário poderia ser dito.

Joyce e Lawrence viveram "processos", além disso, partilhavam a indiferença pelo estilo um do outro. Por exemplo, Lawrence teria manifestado opinião contrária à decisão de Woolsey que absolveu Ulisses. Assim, ao manifestar sua opinião a respeito deste julgamento, Lawrence argumentou que Ulisses era "a coisa mais suja, mais indecente e obscena jamais escrita" (idem). Com isso, Lawrence desconsiderava o estilo de Joyce. Em contrapartida, Joyce se desfazia de $O$ Amante de Lady Chatterley, considerando-a uma obra desprezível. Eis os "processos" de Lawrence e Joyce.

Observando a obra (a colagem) de Martins, reconhecemos marcas que podem remeter ao texto de Pallares-Burke. Os fragmentos verbais de que Martins se apropria e põe em desordem na imagem se aproximam daqueles presentes no discurso da autora. Assim, sugerimos que essa combinação de desenhos e pinturas desarticulados em nova superfície pelo autor dialoga, de forma intertextual, com a obra dela.

Diante desta citação, discutimos mais uma vez a intertextualidade, a partir das considerações de Antoine Compagnon, que ressalta o recorte e a colagem surgidos a partir de uma brincadeira infantil, no entanto, visto como um recurso mais elaborado. Deste modo, "recorte e colagem são experiências fundamentais tais como o papel, das quais a leitura e a escrita não são senão formas derivadas, transitórias, efêmeras" (COMPAGNON, 2007, p. 12).

Compagnon afirma que a citação tem esse poder de realizar o recortar, isto é, retirar um texto de outro contexto e "colar" em um novo suporte, como fez Martins. Assim, "quando cito, extraio, mutilo, desenraizo. Há um objeto primeiro, colocado diante de mim, um texto que li, que leio; e o curso de minha leitura se interrompe numa frase" (idem, p. 13).

Neste viés, citar implica extrair um texto ou um fragmento e convertê-lo em outro texto, no entanto, ao fazer isso essa escritura se converte não mais em fragmento, mas se torna "membro" de um discurso, assim o trecho selecionado, "membro amputado", é um discurso recortado, reitera Compagnon. 
A leitura é o ponto de partida para o início de um ato de destruição e apropriação seja de um objeto, texto, entre outros elementos, algo que apronta o leitor para uma possível imitação ou citação.

Como parte do processo de citação está o grifo que é uma fase da leitura, é através deste que se marcam partes de um texto. Desta forma, o leitor se introduz no corpo textual e deixa suas marcações, rasuras, mutila-o e o torna seu, pois aquilo que se destaca é geralmente o objeto-alvo de suas transformações.

Ao ler um texto busca-se reproduzir aquilo que despertou a atenção. Nesse sentido, o trivial durante uma leitura é "o que eu recorto", pois a citação é "um corpo estranho em meu texto, porque ela não me pertence, porque me aproprio dela. Também a sua assimilação, assim como o enxerto de um órgão, comporta um risco de rejeição contra o qual preciso me prevenir e cuja superação é motivo de júbilo" (idem, p. 37). Esse ato de citar se constitui à semelhança de uma "operação" em que aquele que cita é um "artesão" que realiza uma segregação de partes de um texto, imagem inteira e o transforma deixando as marcas de seu trabalho. Nessa perspectiva, a citação pode ser entendida como uma "cirurgia estética", no qual o escrever é sempre um reescrever, pois a citação trabalha o texto e ao mesmo tempo o desloca, fazendo-o interagir.

Assim, "reescrever um texto, reproduzir um texto a partir de suas iscas, é organizá-las ou associá-las, fazer as ligações ou as transições que se impõem entre os elementos postos em presença um do outro: toda escrita é colagem, glosa, citação e comentário" (idem, p. 39). As ligações se tornam mais difíceis ao apontarmos a citação, pois este recurso requer cuidado, por isso é essencial conservá-las, integrando-as assim como elas se apresentam.

Diante destas considerações, é importante observar como a citação está posta na colagem de Martins. O trecho citado é reagrupado na colagem, podemos notar que as palavras soltas: "Ulisses" e "mais" são apresentadas entre aspas - este sinal tipográfico, como entende Compagnon, teria surgido no decorrer do século XVII por Guillaume que pretendia de certa forma "isolar" um discurso em estilo direto ou uma citação. Assim, "as aspas designam uma re-nunciação ou uma renúncia a um direito de autor. Elas operam uma sutil divisão entre sujeitos e assinalam o lugar em que a silhueta do sujeito da citação se mostra em retirada" (idem, p. 52). Dessa forma, as aspas 
sugerem quem profere o enunciado, elas possibilitam um grau de liberdade ao texto citado.

Martins utiliza as palavras "Ulisses" e "mais” para incorporar a sua colagem toda uma discussão em torno dos processos das obras comentadas. Para isso, como já dito, faz uso de fragmentos do discurso de Pallares-Burke, transformando-o. Entendemos que a versão maxiana é resultado de "um trabalho da citação, uma sobrevivência ou, antes uma manifestação do gesto arcaico do colar-recortar (a caneta reúne as propriedades da tesoura e da cola)" (idem, p. 58). Isso se confirma ao observarmos que as referidas palavras estão grafadas na ilustração.

De maneira similar e ainda fazendo uso da citação, Martins cita outros discursos fragmentados para serem interpretados. Dos processos de Lawrence e Joyce à sintaxe fraturada destaca a transição do discurso anterior para marcas de uísques reconhecidas mundialmente. Entre elas está o "[...] Campeão entre os envelhecidos, o [...] Parr, é produzido pela Macdonald [...] enless e envelhecido por quinze anos [...]. Na sequência ficou o Johnnie Wal Black Label, produzido pela John [...] Sons e um dos uísques mais [...] vendidos em todo o mundo. E envelhecido por doze anos e, entre outras preciosidades, leva em seu blend (mistura dos [...] uíques com os uísques de grão [...])’. Whisky Johnnie Walker Black Label (Walker's Kilmarnock Whisky) é uma marca de licor alcoólico escocês composto por cevada e grãos de cereais produzidos e preparados na Escócia, uma marca pertencente à empresa Diageo. O uísque é uma bebida diferencial e de gosto suave comercializada em todo o mundo, é considerada “envelhecida" por estar no mercado há 12 anos.

Como no exemplo anterior, Martins também incorpora um discurso fragmentado a esta ilustração, possivelmente um recorte de jornal, em que comenta como essa marca de bebida é distinta e bastante consumida. Assim, o trecho: "Johnnie Wal Black Label" surge na colagem e permite a compreensão daquilo que até então estava obscuro, até mesmo a sua posição na colagem é contrária ao discurso de Pallares-Burke. É nesse deslocamento de uma superfície para outra que se promove essa dinâmica da colagem.

É através dos fragmentos verbais deixados na imagem que é possível realizar uma "ativação de sentido", como diz Compagnon, isto é, esses pedaços do verbo revelam o potencial comunicativo da citação. É por meio dessa "manobra" que eles são interpretados. 
Esses discursos são dimensões no novo corpo criado pelo poeta e cada palavra grafada, desenhada ou pintada aparece dispersa e desintegrada. Diante de tantas informações registradas nas colagens, é possível observar que os fragmentos verbais adquirem valor simbólico.

A colagem desenha e rasura o verbo, mas em meio ao caos declara: "a mão na bunda" - uma expressão cotidiana - proferida em diferentes contextos e com várias formas de interpretação. Nesta colagem, entendemos que a imagem e o verbo sugerem a nádega como o objeto de desejo do sujeito que, finalmente, com a única mão que restou de sua inteireza, alcança com a máxima liberdade a nádega - parte do corpo em foco nesta ilustração, e que marca a parte inferior do corpo.

Insistamos ainda para a forma e a nudez que a nádega se exibe. A mão contorna o corpo e quase chega a desaparecer dentro dela, confirmando a profundidade de seu movimento. Assim, a mão delineia o corpo com seu livre acesso e "a mão na bunda" dá ênfase à corpulência despida e chama a atenção para o gesto exibido pelo sujeito, já que o glúteo quase sempre fica encoberto pela vestimenta. A nádega ganha voz e presença. No tronco nu a bunda exerce uma "atração" sobre o sujeito, pois, posicionada de frente, mostra a ação da única mão sendo efetivada, com isso, o sujeito demonstra o seu “domínio" sobre ela.

É na curva inusitada do corpo que o ato indiscreto, diferente, se efetiva, tocar no íntimo talvez tenha sido um anseio proibido, uma particularidade da essência do eu. $\mathrm{O}$ tempo passou, mas deixou no corpo um registro dessa atitude ousada. Assim, o sujeito representa seus anseios individuais, ao firmar a mão no glúteo, como sugerem verbo e imagem. A nádega se exibe e adquire expressividade, apesar de estar atrelada à degradação da forma humana e ao amontoado de palavras soltas que confirmam a decadência da estrutura.

Outro detalhe que está bem próximo ao conteúdo verbal "a mão na bunda” são os traços rasurados que restituem a presença de uma seta que transita no espaço dessa corpulência e que parece apontar para a mulher de óculos (em tons de verde), como já dito. Aparentemente essa seta atravessa o espaço onde está a mulher (sendo sugestivamente "apagada" durante esse contorno) e novamente se direciona para baixo onde está o corpo verbal: "uma amiga de LawRence chegou a levar volumes da obra escondidos na calcinha." 
Na colagem, a nádega também tem função comunicativa: ilustra a palavra e confirma a interação imagem e texto. Ao enfocar o seu caráter simbólico, demonstra o viés comunicativo do verbo, que aponta para uma associação de ideias que ajudam a compor o corpo fraturado. Assim, a bunda coloca em foco um código imagético e linguístico sujeito a interpretações.

O corpo é uma composição falante, que revela em traços dinâmicos os seus atos escritos que referenciam a datas e a palavras soltas: "Bene-dictum". "Pedregu-lhos Tua fala" " G", “28 de Nov, "FRIEDA" são rasuras verbais que foram agregadas ao corpo. $\mathrm{O}$ verbo e as fragmentações são vestígios que permanecem de uma colagem para outra.

\section{Considerações finais}

A colagem constitui, portanto, a confirmação das rupturas e combinações, Martins lida com essa tópica, ao tornar primordial as relações instauradas por suas combinações artísticas que mutilam o corpo em diversas dimensões fraturadas.

Como vimos, Martins cria um corpo aberto a possibilidades criativas, com fraturas e contornos expressivos que constroem corpos fragmentados. A imagem é concretizada pelo corpo verbal e visual, onde se incluem tantos conteúdos expressos: movimentos, anseios, sentimentos, escritas conexas (e desconexas) que se cruzam na sobreposição de corpos formando um espaço de constantes remontes.

Martins faz de sua colagem uma obra em que há fortes indícios de corpos inacabados, com imagens multiformes que dialogam entre si, e com outros objetos e textos artísticos, mantendo diálogos intertextuais. No corpo da colagem, estão os lastros, isto é, as fraturas que decompõem os sujeitos em porções mínimas, fragmentadas, desfiguradas.

\section{REFERÊNCIAS}

CAVALCANTE, Vasco. Max Martins 80 anos - Homenagem da SOL Informática. [Belém de 2015]. Inédito. Entrevista concedida a Márcia Souza.

CHEVALIER, Jean; CHEERBRANT, Alain. Dicionário de símbolos. Rio de Janeiro: José Olímpio, 1996. 
COMPAGNON Antoine. $O$ trabalho da citação. $2^{\text {a }}$ ed. Trad. de Cleonice P. B. Mourão. Belo Horizonte: UFMG, 2007.

MATESCO, Viviane. Corpo, imagem e representação. - Rio de Janeiro: Jorge Zahar. Ed., 2009.

EIRÓ, Jorge. Diários de Max Martins. A Plástica Entre Parêntesis. Disponível em: http://www.culturapara.art.br/maxmartins/maxdiario.htm. Acesso em: 2 fev. 2013.

MAX MARTINS 80 ANOS. Homenagem aos 80 anos do poeta. Belém: Fotum Fotografia e eventos. DVD com tiragem limitada. Realização Sol Informática, julho, 2006.

ORTEGA Y GASSET, José. A desumanização da arte. Tradução de Ricardo Araújo. Revisão técnica de Vicente Cechelero. - 2ª ed. - São Paulo: Cortez, 1999. 